\title{
Prussian White Analogues as Promising Cathode for Non-Aqueous Potassium-Ion Batteries
}

Xianyong Wu, Zelang Jian, Zhifei Li, and Xiulei Ji*

Department of Chemistry, Oregon State University, Corvallis, OR, 97331, United States

[*] Corresponding author. E-mail address: david.ji@ oregonstate.edu

\begin{abstract}
We prepared Prussian white analogues- $\mathrm{K}_{\mathrm{x}} \mathrm{MFe}(\mathrm{CN})_{6} \cdot \mathrm{mH}_{2} \mathrm{O}(\mathrm{M}=\mathrm{Fe}, \mathrm{Co}, \mathrm{Ni}$, or $\mathrm{Cu})$. These compounds are investigated as cathode materials for potassium-ion batteries with a non-aqueous electrolyte. Each of these materials exhibits different K-ion storage properties with reversible capacity values ranging from 35 to $110 \mathrm{mAh} \mathrm{g}^{-1}$ at high potentials above $3.2 \mathrm{~V} v s$. $\mathrm{K}^{+} / \mathrm{K}$. Among them, $\mathrm{FeFe}$-Prussian white, $\mathrm{K}_{1.68} \mathrm{Fe}_{1.09} \mathrm{Fe}(\mathrm{CN})_{6} \cdot 2 \cdot 1 \mathrm{H}_{2} \mathrm{O}$, exhibits the highest reversible capacity of $110 \mathrm{mAh} \mathrm{g}^{-1}$ and stable cycling performance in contrast to rapid capacity fading of other analogues. Our results demonstrate a remarkable potential of this family of cathode materials for the emerging potassium-ion batteries.
\end{abstract}

\section{Keywords:}

Potassium-ion battery $\bullet$ Cathode $\bullet$ Prussian blue $\bullet$ Prussian white

\section{Introduction}

Batteries employing inexpensive Earth-abundant elements have recently received considerable attention [1,2]. Shadowed by the world-wide effort on sodium-ion batteries (NIBs), potassium-ion batteries (KIBs) have received little attention, which is seemingly due to the higher mass of $\mathrm{K}$-ion as well as its large size [3]. However, when considering a full-cell scale, the mass burden of K-ions renders KIBs only 5 to $10 \%$ heavier than NIBs if the electrodes of the two types of devices exhibit similar capacity values [3]. Indeed, indiscriminate to all emerging batteries, the challenge comes from identifying suitable electrode materials, where KIBs represent no exception. 
The recent interests on KIBs have been stimulated by the progress made on the anode side [4-14]. However, further progress of KIBs faces the hurdle on the cathode side, where there have been very few choices of cathode materials. Eftekhari reported a Prussian blue KIB cathode, $\mathrm{K}_{\mathrm{x}} \mathrm{Fe}_{2}(\mathrm{CN})_{6}$, which exhibited a reversible capacity of $\sim 78 \mathrm{mAh} \mathrm{g}^{-1}$ and impressive cycling life [15]. Cui et al. investigated various Prussian blue analogues as electrodes in KIBs that contain aqueous electrolytes $[16,17]$. Recently, a few more cathode candidates were reported, including layered oxides, such as $\mathrm{K}_{0.3} \mathrm{MnO}_{2}$ [18] and $\mathrm{K}_{0.7} \mathrm{Fe}_{0.5} \mathrm{Mn}_{0.5} \mathrm{O}_{2}$ [19], as well as a couple of organic solids, such as Perylenetetracarboxylic dianhydride (PTCDA) [20] and Poly(anthraquinonyl sulfide) (PAQS) [21]. Yet, these cathode materials often do not contain sufficient K-ions to extract, which fundamentally limits the choice of anodes. As another issue, the operation potentials of these materials are modest, which on average are at 2.0-2.5 V vs. $\mathrm{K}^{+} / \mathrm{K}$, thus restricting the energy density of full cell devices. Therefore, it is highly desirable to identify potassium-containing, high-potential cathode materials. Very recently, Xu et al. reported $\mathrm{K}_{3} \mathrm{~V}_{2}\left(\mathrm{PO}_{4}\right)_{3}$ as a $\mathrm{KIB}$ cathode with a high reaction potential above $3.6 \mathrm{~V}$ and a capacity of $54 \mathrm{mAh} \mathrm{g}^{-1}[22]$.

The primary challenge of identifying cathode materials for KIBs might be the much larger radius of K-ion $(1.38 \AA$ ) vs. Li-ion $(0.76 \AA)$ and Na-ion (1.02 $\AA$ ) [23], which is fortunately not an issue for Prussian blue analogues. In 2016, Zhang et al. reported that a $\mathrm{K}_{0.22} \mathrm{Fe}\left[\mathrm{Fe}(\mathrm{CN})_{6}\right]_{0.805} \cdot 4.01 \mathrm{H}_{2} \mathrm{O}$ cathode could deliver a reversible capacity of $76.7 \mathrm{mAh} \mathrm{g}^{-1}$ at 3.2 V with capacity retention of $95.4 \%$ after 50 cycles [24]. Note that this Prussian blue electrode still does not contain a good stoichiometry of removable K-ions. It is well known that Prussian white theoretically contains one more extractable K-ion than Prussian blue in the open framework, which renders double capacity during the initial charge of a full cell [25-29]. Most recently, Goodenough et al. reported $\mathrm{K}_{1.89} \mathrm{Mn}\left[\mathrm{Fe}(\mathrm{CN})_{6}\right]_{0.92} \cdot 0.75 \mathrm{H}_{2} \mathrm{O}$ as a low cost and high energy potassium-ion cathode, which realized a high capacity of $142 \mathrm{mAh} \mathrm{g}^{-1}$ and high reaction potential of 3.6 V [25]. This pioneering study indicates the feasibility of utilizing Prussian white analogues as low-cost and high-performing cathode materials for KIBs.

In this communication, we, for the first time, report the performance of several Prussian white analogues as cathode in nonaqueous $\mathrm{KIBs}-\mathrm{K}_{\mathrm{x}} \mathrm{MFe}(\mathrm{CN})_{6} \cdot \mathrm{mH}_{2} \mathrm{O}(\mathrm{M}=\mathrm{Fe}, \mathrm{Co}, \mathrm{Ni}$, or $\mathrm{Cu})$, which were prepared by a simple precipitation method. 


\section{Experimental}

We aim to synthesize four Prussian white analogues: $\mathrm{K}_{2} \mathrm{FeFe}(\mathrm{CN})_{6}, \mathrm{~K}_{2} \mathrm{CoFe}(\mathrm{CN})_{6}$, $\mathrm{K}_{2} \mathrm{NiFe}(\mathrm{CN})_{6}$, and $\mathrm{K}_{2} \mathrm{CuFe}(\mathrm{CN})_{6}$ by a simple precipitation method. Typically, $0.1 \mathrm{~mol} \mathrm{~L} \mathrm{MCl}_{2}$ $\left(\mathrm{M}=\mathrm{Fe}, \mathrm{Co}, \mathrm{Ni}\right.$, and $\mathrm{Cu}$ ) solution was dropwise added into $0.1 \mathrm{~mol} \mathrm{~L}^{-1} \mathrm{~K} / \mathrm{Fe}(\mathrm{CN})_{6}$ solution under stirring. After four hours' reaction, the precipitate was centrifuged, rinsed, and dried in an oven at $80^{\circ} \mathrm{C}$ overnight. Due to the presence of structural defects, common in room-temperature precipitation reactions, the actual chemical formula of Prussian white analogues may deviate from the stoichiometry of $\mathrm{K}_{2} \mathrm{MFe}(\mathrm{CN})_{6}$, which can be analyzed by inductively coupled plasma optical emission spectrometry (ICP-OES, PerkinElmer 2100 DV) on K, M, and Fe elements. We also conducted thermogravimetric analysis (TGA, SDT Q600) on water content. We determined their formula to be $\mathrm{K}_{1.68} \mathrm{Fe}_{1.09} \mathrm{Fe}(\mathrm{CN})_{6} \cdot 2.1 \mathrm{H}_{2} \mathrm{O}, \mathrm{K}_{1.55} \mathrm{Co}_{0.88} \mathrm{Fe}(\mathrm{CN}){ }_{6} \cdot 3.2 \mathrm{H}_{2} \mathrm{O}$, $\mathrm{K}_{1.51} \mathrm{Ni}_{1.05} \mathrm{Fe}(\mathrm{CN})_{6} \cdot 3.3 \mathrm{H}_{2} \mathrm{O}$, and $\mathrm{K}_{1.40} \mathrm{Cu}_{0.93} \mathrm{Fe}(\mathrm{CN})_{6} \cdot 4.5 \mathrm{H}_{2} \mathrm{O}$, respectively. Interestingly, the content of crystal water in these Prussian white analogues increases along the atomic number: $\mathrm{Fe}<\mathrm{Co}<\mathrm{Ni}<\mathrm{Cu}$. We refer to the four obtained Prussian white samples as FeFe-PW, CoFe-PW, $\mathrm{NiFe}-\mathrm{PW}$, and CuFe-PW, respectively. The theoretical capacities of FeFe-PW, CoFe-PW, NiFePW, and CuFe-PW are 119.7, 108.2, 70.7, and 59.1 $\mathrm{mAh} \mathrm{g}^{-1}$, respectively, based on the content of $\mathrm{K}$-ions in the structures, if we assume that the transition metal redox couples, $\mathrm{M}^{3+} / \mathrm{M}^{2+}(\mathrm{M}=\mathrm{Fe}$ and $\mathrm{Co}$ ), are active but $\mathrm{Ni}^{3+} / \mathrm{Ni}^{2+}$ and $\mathrm{Cu}^{3+} / \mathrm{Cu}^{2+}$ are inactive. It is known that $\mathrm{Ni}^{3+/} \mathrm{Ni}^{2+}$ is inactive in both $\mathrm{Li}$ and $\mathrm{Na}$ analogues of Prussian blue [27, 30].

We collected powder x-ray diffraction (XRD) patterns on a Rigaku Ultima IV Diffractometer with $\mathrm{Cu}$ Ka irradiation $(\lambda=1.5406 \AA)$. The electrodes of Prussian white materials were composed of $70 \mathrm{wt} \%$ of Prussian white active mass, $20 \mathrm{wt} \%$ Super P, and $10 \mathrm{wt} \%$ Polyvinylidene fluoride (PVdF). The electrode slurry was cast on Al foil, where the typical loading of active mass is $\sim 2 \mathrm{mg} / \mathrm{cm}^{2}$. Coin cells (2032) were assembled in an argon-filled glovebox, which contains Prussian white working electrode, potassium metal counter/reference electrode, glass fiber membrane as a separator, and an electrolyte of $0.8 \mathrm{~mol} \mathrm{~L}^{-1} \mathrm{KPF}_{6}$ in propylene carbonate (PC) with $4 \mathrm{wt} \%$ fluoroethylene carbonate (FEC) additive. Cyclic voltammetry $(\mathrm{CV})$ tests were performed on a VMP-3 multi-channel workstation at a scan rate of $0.1 \mathrm{mV} \mathrm{s}^{-1}$. The galvanostatic charge/discharge tests were carried out on a Maccor system at room temperature. The voltage range for electrochemical tests is $2.0-4.5 \mathrm{~V} v s . \mathrm{K}^{+} / \mathrm{K}$. 


\section{Results and discussion}

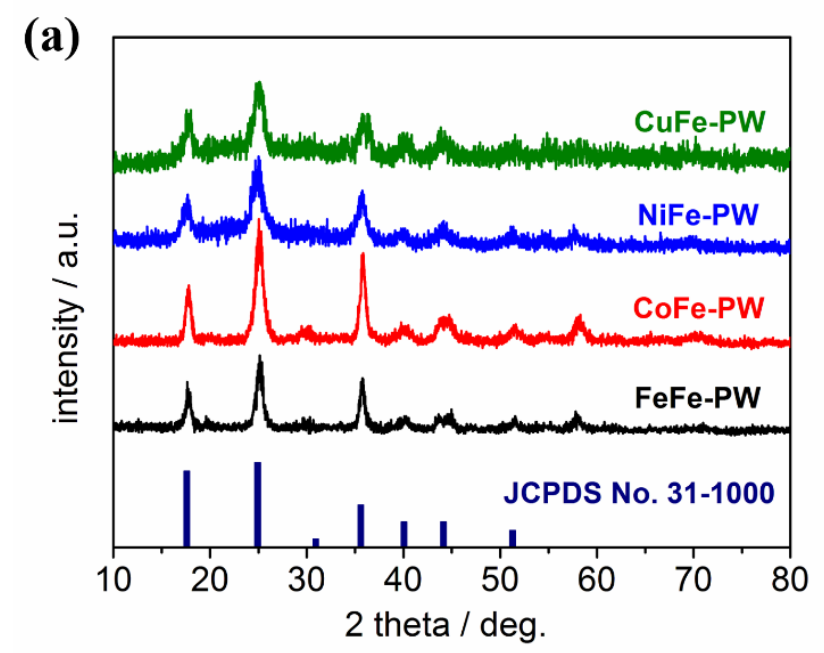

(b)

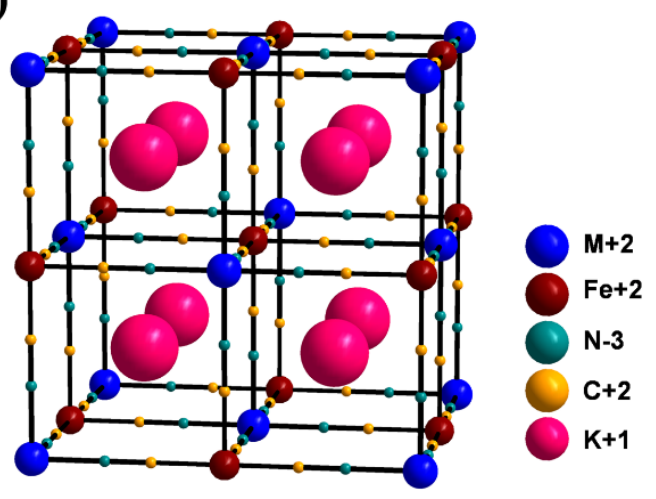

Fig. 1. (a) XRD patterns of the four Prussian white analogues in comparison with the standard diffraction pattern of $\mathrm{K}_{2} \mathrm{CoFe}(\mathrm{CN})_{6}$ (JCPDS No. 31-1000); (b) A schematic of the crystal structure of $\mathrm{K}_{2} \mathrm{MFe}(\mathrm{CN})_{6}, \mathrm{M}=\mathrm{Fe}, \mathrm{Co}, \mathrm{Ni}$, and $\mathrm{Cu}$.

Prussian white samples were prepared by a conventional precipitation reaction between $\mathrm{MCl}_{2}(\mathrm{M}=\mathrm{Fe}, \mathrm{Co}, \mathrm{Ni}, \mathrm{Cu})$ and $\mathrm{K}_{4} \mathrm{Fe}(\mathrm{CN})_{6}$ in an aqueous solution. As the filtered precipitates were only heated at $80{ }^{\circ} \mathrm{C}$, they still contain crystal water. In this study, we choose to reveal the intrinsic electrochemical behavior of these as-obtained Prussian white materials. The XRD results (Fig. 1a) suggest that all the obtained samples exhibit typical Prussian white patterns, which can be assigned to a face-centered cubic structure (FCC, space group Fm-3m). In such a structure, $\mathrm{Fe}^{2+}$ and $\mathrm{M}^{2+}$ ions are alternately six-fold coordinated to the carbon and nitrogen end of the cyanide ligands, respectively, which constitutes a three-dimensional open framework with large interstitial cavities to accommodate K-ions and possibly water molecules (Fig. 1b) [27]. For FeFe-PW, there is minor phase transformation, as indicated by the peak-split around $\sim 40$ and $\sim 45^{\circ}[25,26]$. Such phase transformation has also been observed in other studies, where high Kion content in Prussian white structure will induce the cubic lattice to transform to a monoclinic one $[25,26]$. 

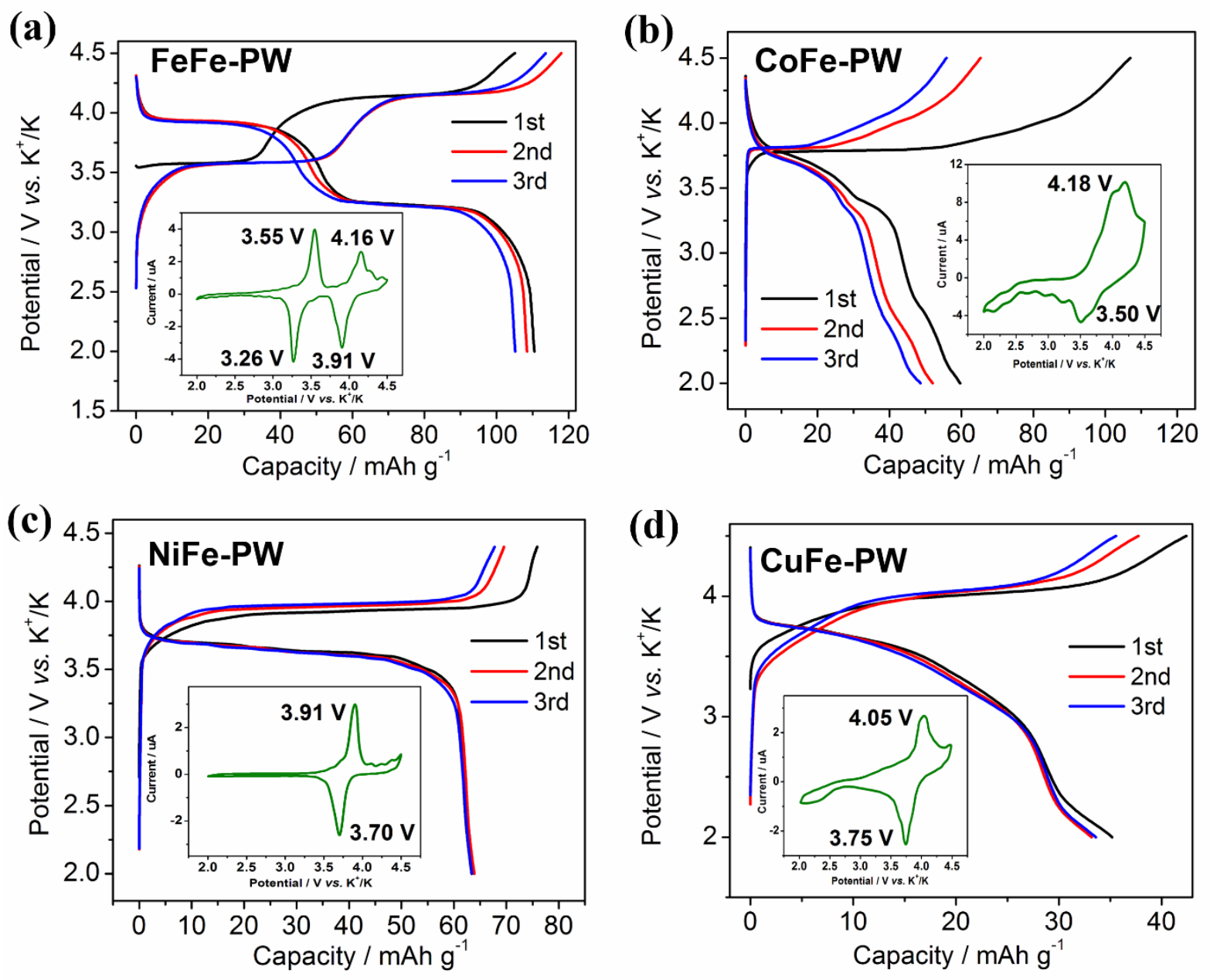

Fig. 2. Charge/discharge potential profiles of Prussian white electrodes: (a) FeFe-PW, (b) CoFe$\mathrm{PW}$, (c) NiFe-PW, and (d) CuFe-PW at the current density of $20 \mathrm{~mA} \mathrm{~g}^{-1}$. The inset are typical $\mathrm{CV}$ curves of these $\mathrm{PW}$ electrodes collected at the scan rate of $0.1 \mathrm{mV} / \mathrm{s}$.

In principle, $\mathrm{K}_{2} \mathrm{MFe}(\mathrm{CN})_{6}$ can undergo a two-electron-transfer reaction, which converts Prussian white (PW) to Berlin green (BG), based on the $\mathrm{M}^{3+} / \mathrm{M}^{2+}(\mathrm{M}=\mathrm{Fe}, \mathrm{Co})$ and $\mathrm{Fe}^{3+} / \mathrm{Fe}^{2+}$ redox couples by the following reaction:

$$
\mathrm{K}_{2} \mathrm{M}^{\mathrm{II}} \mathrm{Fe}^{\mathrm{II}}(\mathrm{CN})_{6}(\mathrm{PW}) \leftrightarrow \mathrm{M}^{\mathrm{III}} \mathrm{Fe}^{\mathrm{III}}(\mathrm{CN})_{6}(\mathrm{BG})+2 \mathrm{~K}^{+}+2 \mathrm{e}^{-}
$$

This corresponds to a very high theoretical capacity of $\sim 150 \mathrm{mAh}^{-1}$ for compounds, i.e., $\mathrm{K}_{2} \mathrm{FeFe}(\mathrm{CN})_{6}$ and $\mathrm{K}_{2} \mathrm{CoFe}(\mathrm{CN})_{6}$. We tested the as-obtained Prussian white electrodes by $\mathrm{CV}$ measurements at a scan rate of $0.1 \mathrm{mV} \mathrm{s}^{-1}$ in the potential range of $2-4.5 \mathrm{~V} v s . \mathrm{K}^{+} / \mathrm{K}$. As shown, 
FeFe-PW electrode demonstrates a typical two K-ion extraction/insertion behavior, whereas $\mathrm{CoFe}-\mathrm{PW}$, NiFe-PW and CuFe-PW electrodes seem to operate by a one-electron reaction mechanism (Fig 2 inset).

As depicted in Fig. 2a, FeFe-PW displays two distinct charge/discharge plateaus at 4.1/3.9 $\mathrm{V}$ and 3.6/3.2 V, which can be attributed to the $\mathrm{Fe}^{3+} / \mathrm{Fe}^{2+}$ redox couples on the carbon side and on the nitrogen side, respectively [27-29]. It is noteworthy that the discharge potentials of 3.9 and 3.2 $\mathrm{V}$ of $\mathrm{K}_{\mathrm{x}} \mathrm{FeFe}-\mathrm{PW}$ are higher than those of $\mathrm{Na}_{\mathrm{x}} \mathrm{FeFe}-\mathrm{PW}, 3.3$ and $3.0 \mathrm{~V}$, in Na-ion batteries [29]. This may have to do with the facts that the standard potential of $\mathrm{K}^{+} / \mathrm{K}$ is $\sim 0.3 \mathrm{~V}$ lower than that of $\mathrm{Na}^{+} / \mathrm{Na}$ in PC solvent [31] and that the Gibbs free energy may be lower when $\mathrm{K}$-ions are incorporated into the $\mathrm{FeFe}(\mathrm{CN})_{6}$ framework [32]. The first-cycle charge/discharge capacity of 105.1/110.5 $\mathrm{mAh} \mathrm{g}^{-1}$ for FeFe-PW gives rise to an initial coulombic efficiency of $105.1 \%$, which is likely due to the mixed oxidation states of Fe (II) and Fe (III) of the iron site coordinated to nitrogen end of cyanide, thus resulting in a shorter low-potential plateau during depotassiation [29]. However, the following discharge (potassiation) may form a Prussian white structure with more K-ions inserted than its pristine form, which would give rise to a coulombic efficiency more than $100 \%$. In the third cycle, the discharge capacity is still above $105 \mathrm{mAh} \mathrm{g}^{-1}$, indicating good K-insertion reversibility of FeFe-PW. Importantly, the initial discharge capacity of FeFe-PW compound is as high as $110.5 \mathrm{mAh} \mathrm{g}^{-1}$, which corresponds to $92 \%$ utilization of its theoretical capacity of $119.7 \mathrm{mAh} \mathrm{g}^{-1}$ when assuming intercalation/deintercalation of 1.68 potassium ions. If more potassium ions are present in the FeFe-PW lattice and all crystal water molecules can be eliminated, higher K-storage capacity can be expected.

Fig. 2 b-d shows the charge/discharge potential profiles of CoFe-PW, NiFe-PW, and CuFePW electrodes, respectively. Interestingly, CoFe-PW demonstrates a low discharge capacity of only $\sim 60 \mathrm{mAh} \mathrm{g}^{-1}$, which corresponds to a one-electron transfer mechanism (Fig. 2b). However, the sodium analogue of $\mathrm{Na}_{2} \mathrm{CoFe}(\mathrm{CN})_{6}$ can deliver a complete 2-Na capacity of $\sim 150 \mathrm{mAh} \mathrm{g}^{-1}$ [33]. We hypothesize that the disparity between Na-CoFe-PW and K-CoFe-PW may be resulted from the fact that $\mathrm{K}$-ions constitute a more stable structure with more negative Gibbs free energy with strong bonding between $\mathrm{K}$-ions and cyanide ions, where the electron density might be more attracted toward K-ions. Thus, the inductive effect would cause the redox potential of $\mathrm{Co}(\mathrm{III}) / \mathrm{Co}(\mathrm{II})$ to rise in this structure, where below the upper cutoff potential, $\mathrm{Co}(\mathrm{II})$ cannot be oxidized in galvanostatic depotassiation [34]. The very low first-cycle coulombic efficiency of 
K-CoFe-PW ( $\sim 56 \%)$ may involve the decomposition of crystal water, as suggested in recent NIB studies [27-29]. For NiFe-PW, it presents a very flat charge/discharge plateau at $\sim 4.0 / 3.6 \mathrm{~V}$, suggesting a two-phase reaction mechanism (Fig. 2c) [29]. Its reversible K-insertion capacity is $63.4 \mathrm{mAh} \mathrm{g}^{-1}$, which is very close to the value in an aqueous potassium electrolyte [16]. The discharge capacity remained constant at $\sim 63.4 \mathrm{mAh} \mathrm{g}^{-1}$ at the third cycle, implying a reversible K-insertion process. Fig. 2d demonstrates the charge/discharge profiles of CuFe-PW electrode, where the reversible specific capacity of $35.2 \mathrm{mAh} \mathrm{g}^{-1}$ is the lowest among all four Prussian white materials. This may relate to the fact that it has the highest number of crystal water molecules $\left(4.5 \mathrm{H}_{2} \mathrm{O}\right)$.
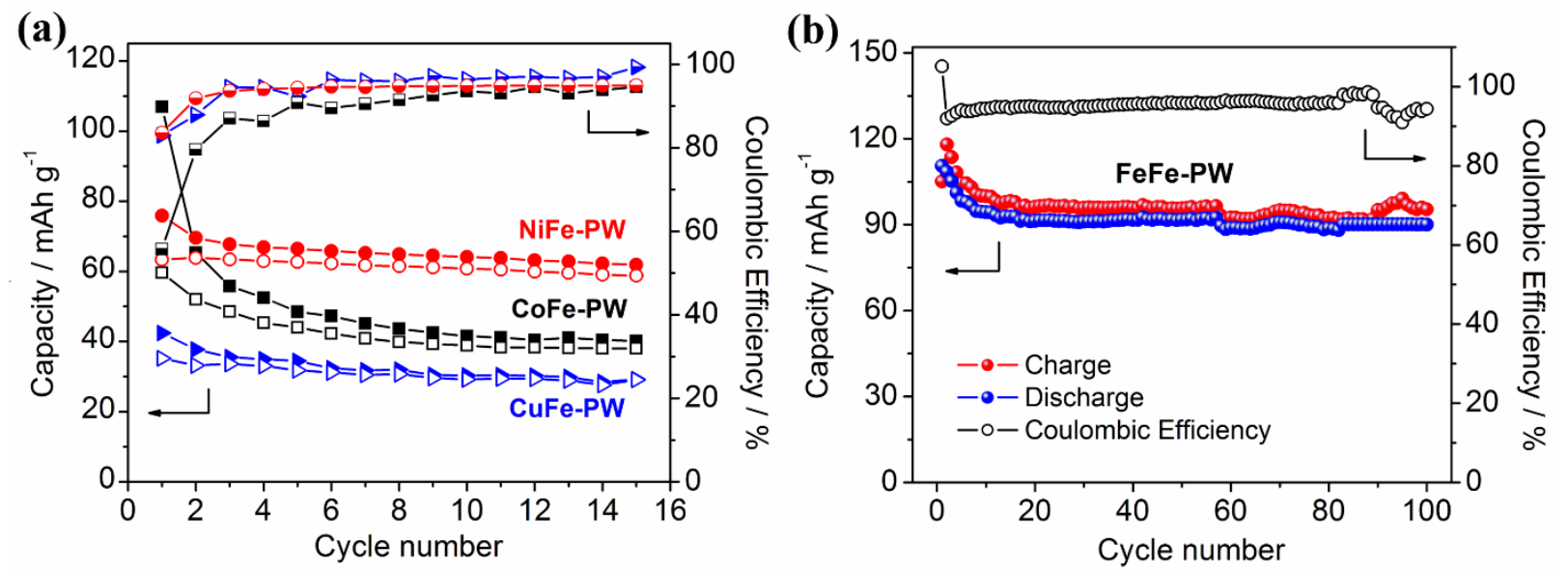

Fig. 3. Cycling performance of Prussian white electrodes at the current density of $20 \mathrm{~mA} \mathrm{~g}^{-1}$ : (a) CoFe-PW, NiFe-PW and CuFe-PW, (b) FeFe-PW.

These Prussian white analogues exhibit vastly different cycling performance at a current density of $20 \mathrm{~mA} \mathrm{~g}^{-1}$ albeit they were prepared and treated at the same conditions. As Fig. 3a shows, CoFe-PW suffer rapid capacity fading, where only after 15 cycles, its capacity values fade to $64 \%$ of the original value. NiFe-PW and CuFe-PW exhibit relatively stable cycling, where their capacity retention after 15 cycles is $93 \%$, and $83 \%$, respectively. Interestingly, the cycling life of FeFe-PW electrode is impressive, where after 100 cycles, its capacity decreases from 110.5 to $90.4 \mathrm{~mA} \mathrm{~h} \mathrm{~g}^{-1}$, corresponding to a high capacity retention of $81 \%$ (Fig. 3b). The cycling difference of these compounds may be associated with many factors such as water 
content, crystal defects and crystal integrity, where water decomposition, structural collapse and metal ions dissolution may occur during charge/discharge process [27-29].

\section{Conclusions}

We have prepared four Prussian white materials and investigated their cathode performance for KIBs in a non-aqueous electrolyte, which provides a good picture of these materials for a general trend. Among these materials, FeFe-PW exhibits a high reversible capacity of $110 \mathrm{mAh}$ $\mathrm{g}^{-1}$ with two plateaus at high potentials of 3.9 and $3.2 \mathrm{~V}$ vs. $\mathrm{K}^{+} / \mathrm{K}$, and relatively stable cycling performance. Note that the capacity values of these materials would be underestimated due to the existence of crystal water and its associated decomposition. In further studies, with crystal water removed, not only the capacity value but also the cycling life as well as the coulombic efficiency values of these materials are expected to be greatly improved. Prepared by a straightforward aqueous precipitation method at room temperature, Prussian white analogues are low-cost and high performance non-aqueous KIB cathode materials.

\section{Acknowledgements}

X.J. is thankful for the financial supports from National Science Foundation Award No.1551693. We thank Professor Douglas A. Keszler for the XRD measurements. We appreciate Professor May Nyman for the thermogravimetric analysis. We are grateful to Ms. Gloria M. Ambrowiak and Ms. Shannon B. Andrews for their kind help on the ICP-OES studies.

\section{References}

[1] Y. Zhao, C. Han, J. Yang, J. Su, X. Xu, S. Li, L. Xu, R. Fang, H. Jiang, X. Zou, Stable alkali metal ion intercalation compounds as optimized metal oxide nanowire cathodes for lithium batteries, Nano Lett., 15 (2015) 2180-2185.

[2] X. Wang, C. Niu, J. Meng, P. Hu, X. Xu, X. Wei, L. Zhou, K. Zhao, W. Luo, M. Yan, Novel $\mathrm{K}_{3} \mathrm{~V}_{2}\left(\mathrm{PO}_{4}\right)_{3} / \mathrm{C}$ Bundled Nanowires as Superior Sodium-Ion Battery Electrode with Ultrahigh Cycling Stability, Adv. Energy Mater., 5 (2015) 1500716. 
[3] A. Eftekhari, Z. Jian, X. Ji, Potassium secondary batteries, ACS Appl. Mater. Interfaces, (2016), doi: 10.1021/acsami.6b07989.

[4] Y. Liu, F. Fan, J. Wang, Y. Liu, H. Chen, K. L. Jungjohann, Y. Xu, Y. Zhu, D. Bigio, T. Zhu, C. Wang, In situ transmission electron microscopy study of electrochemical sodiation and potassiation of carbon nanofibers, Nano Lett., 14 (2014) 3445-3452.

[5] Z. Jian, W. Luo, X. Ji, Carbon electrodes for K-Ion batteries, J. Am. Chem. Soc., 137 (2015) 11566-11569.

[6] S. Komaba, T. Hasegawa, M. Dahbi, K. Kubota, Potassium intercalation into graphite to realize high-voltage/high-power potassium-ion batteries and potassium-ion capacitors, Electrochem. Commun., 60 (2015) 172-175.

[7] W. Luo, J. Wan, B. Ozdemir, W. Bao, Y. Chen, J. Dai, H. Lin, Y. Xu, F. Gu, V. Barone, L. $\mathrm{Hu}$, Potassium ion batteries with graphitic materials, Nano Lett., 15 (2015) 7671-7677.

[8] J. Zhao, X. Zou, Y. Zhu, Y. Xu, C. Wang, Electrochemical intercalation of potassium into graphite, Adv. Funct. Mater., 26 (2016) 8103-8110.

[9] K. Share, A. P. Cohn, R. Carter, B. Rogers, C. L. Pint, Role of nitrogen doped graphene for improved high capacity potassium ion battery anodes, ACS Nano, 10, (2016), 9738-9744.

[10] Z. Jian, Z. Xing, C. Bommier, Z. Li, X. Ji, Hard carbon microspheres: potassium-ion anode versus sodium-ion anode, Adv. Energy Mater., 6 (2016) 1501874-150878.

[11] K. Share, A. P. Cohn, R.E. Carter, C.L. Pint, Mechanism of potassium ion intercalation staging in few layered graphene from in situ Raman spectroscopy, Nanoscale, 8 (2016) 1643516439.

[12] I. Sultana, T. Ramireddy, M. M. Rahman, Y. Chen, A.M. Glushenkov, Tin-based composite anodes for potassium-ion batteries, Chem. Commun., 52 (2016) 9279-9282.

[13] J. Han, M. Xu, Y. Niu, G.-N. Li, M. Wang, Y. Zhang, M. Jia, C. Ming Li, Exploration of $\mathrm{K}_{2} \mathrm{Ti}_{8} \mathrm{O}_{17}$ as an anode material for potassium-ion batteries, Chem. Commun., 52 (2016) 1127411276 .

[14] J. Han, Y. Niu, S. J. Bao, Y. N. Yu, S. Y. Lu, M. Xu, Nanocubic $\mathrm{KTi}_{2}\left(\mathrm{PO}_{4}\right)_{3}$ electrodes for potassium-ion batteries, Chem. Commun., 52 (2016) 11661-11664.

[15] A. Eftekhari, Potassium secondary cell based on Prussian blue cathode, J. Power Sources, 126 (2004) 221-228. 
[16] C. D. Wessells, S. V. Peddada, R. A. Huggins, Y. Cui, Nickel hexacyanoferrate nanoparticle electrodes for aqueous sodium and potassium ion batteries, Nano. Lett., 11 (2011) 5421-5425. [17] C. D. Wessells, R. A. Huggins, Y. Cui, Copper hexacyanoferrate battery electrodes with long cycle life and high power, Nat. Commun., 2 (2011) 550.

[18] C. Vaalma, G. A. Giffin, D. Buchholz, S. Passerini, Non-aqueous K-ion battery based on layered $\mathrm{K}_{0.3} \mathrm{MnO}_{2}$ and hard carbon/carbon black, J. Electrochem. Soc., 163 (2016) A1295A1299.

[19] X. Wang, X. Xu, C. Niu, J. Meng, M. Huang, X. Liu, Z. Liu, L. Mai, Earth abundant $\mathrm{Fe} / \mathrm{Mn}$-based layered oxide interconnected nanowires for advanced K-Ion full batteries, Nano Lett, (2016), doi: 10.1021/acs.nanolett.6b04611.

[20] Z. Xing, Z. Jian, W. Luo, Y. Qi, C. Bommier, E.S. Chong, Z. Li, L. Hu, X. Ji, A perylene anhydride crystal as a reversible electrode for K-ion batteries, Energy Storage Materials, 2 (2016) 63-68.

[21] Z. Jian, Y. Liang, I. A. Rodríguez-Pérez, Y. Yao, X. Ji, Poly(anthraquinonyl sulfide) cathode for potassium-ion batteries, Electrochem. Commun., 71 (2016) 5-8.

[22] J. Han, G.-N. Li, F. Liu, M. Wang, Y. Zhang, L. Hu, C. Dai, M. Xu, Investigation of $\mathrm{K}_{3} \mathrm{~V}_{2}\left(\mathrm{PO}_{4}\right)_{3} / \mathrm{C}$ nanocomposites as high-potential cathode materials for potassium-ion batteries, Chem. Commun., 53 (2017) 1805-1808.

[23] R. t. Shannon, Revised effective ionic radii and systematic studies of interatomic distances in halides and chalcogenides, Acta Cryst. A: Crystal physics, diffraction, theoretical and general crystallography, 32 (1976) 751-767.

[24] C. Zhang, Y. Xu, M. Zhou, L. Liang, H. Dong, M. Wu, Y. Yang, Y. Lei, Potassium Prussian blue nanoparticles: a low-cost cathode material for potassium-ion batteries, Adv. Funct. Mater., (2016) 1604307.

[25] L. Xue, Y. Li, H. Gao, W. Zhou, X. Lü, W. Kaveevivitchai, A. Manthiram, J.B.

Goodenough, A Low-Cost High-Energy Potassium Cathode, J. Am. Chem. Soc., (2017) doi: 10.1021/jacs.6b12598.

[26] D. Su, A. McDonagh, S. Z. Qiao, G. Wang, High-capacity aqueous potassium-ion batteries for large-scale energy storage, Adv. Mater., 29 (2017), doi: 10.1002/adma.201604007. [27] Y. Lu, L. Wang, J. Cheng, J. B. Goodenough, Prussian blue: a new framework of electrode materials for sodium batteries, Chem. Commun., 48 (2012) 6544-6546. 
[28] X. Wu, W. Deng, J. Qian, Y. Cao, X. Ai, H. Yang, Single-crystal FeFe $(\mathrm{CN})_{6}$ nanoparticles: a high capacity and high rate cathode for Na-ion batteries, J. Mater. Chem. A, 1 (2013) 1013010134.

[29] Y. You, X.-L. Wu, Y.-X. Yin, Y.-G. Guo, High-quality Prussian blue crystals as superior cathode materials for room-temperature sodium-ion batteries, Energy Environ. Sci., 7 (2014) 1643-1647.

[30] M. Omarova, A. Koishybay, N. Yesibolati, A. Mentbayeva, N. Umirov, K. Ismailov, D. Adair, M.-R. Babaa, I. Kurmanbayeva, Z. Bakenov, Nickel hexacyanoferrate nanoparticles as a low cost cathode material for lithium-ion batteries, Electrochim. Acta, 184 (2015) 58-63.

[31] N. Matsuura, K. Umemoto, Z.i. Takeuchi, Standard potentials of alkali metals, silver, and thallium metal/ion couples in N, N'-dimethylformamide, dimethyl sulfoxide, and propylene carbonate, Bull. Chem. Soc. Jpn., 47 (1974) 813-817.

[32] C. Ling, J. Chen, F. Mizuno, First-principles study of alkali and alkaline earth ion intercalation in iron hexacyanoferrate: the important role of ionic radius, J. Phys. Chem. C, 117 (2013) 21158-21165.

[32] X. Wu, M. Sun, S. Guo, J. Qian, Y. Liu, Y. Cao, X. Ai, H. Yang, Vacancy-Free Prussian Blue Nanocrystals with High Capacity and Superior Cyclability for Aqueous Sodium-Ion Batteries, ChemNanoMat, 1 (2015) 188-193.

[34] T. Matsuda, J. Kim, Y. Moritomo, Symmetry switch of cobalt ferrocyanide framework by alkaline cation exchange, J. Am. Chem. Soc., 132 (2010) 12206-12207. 


\section{Graphical Abstract}

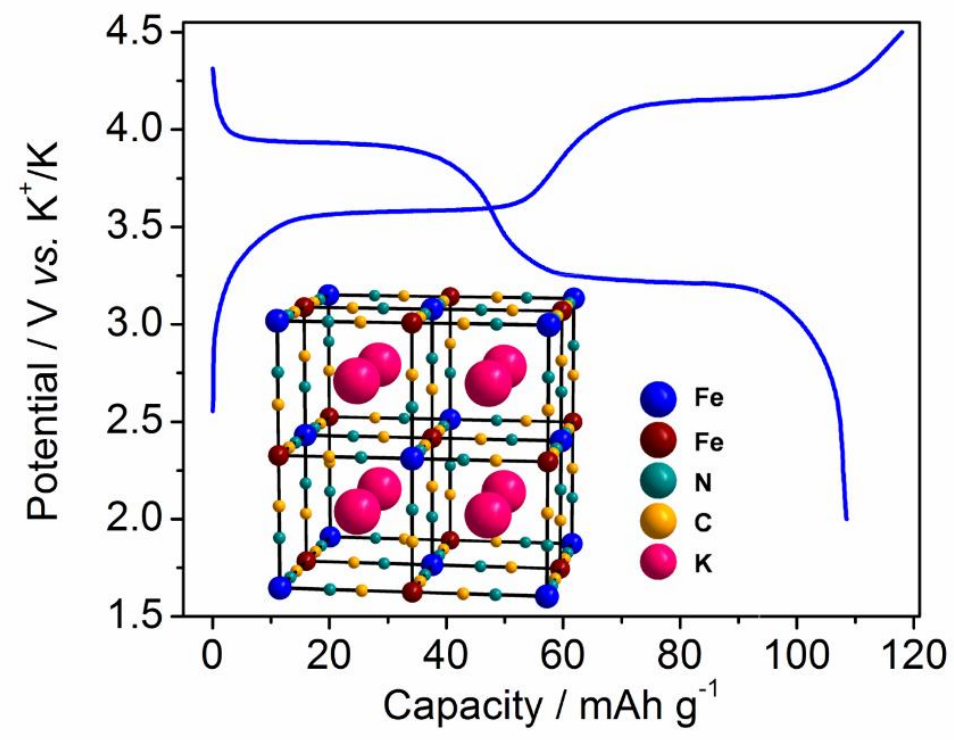

